Bangl. J. Vet. Med. (2007). 5 (1 \& 2): 115-119

\title{
PREVALENCE OF ENTEROTOXIGENIC AND TOXIC SHOCK SYNDROME TOXIN-1 PRODUCING COAGULASE POSITIVE STAPHYLOCOCCUS AUREUS IN HUMAN AND THEIR CHARACTERIZATION
}

\author{
M. J. Islam, M. S. Uddin ${ }^{1}$, M. S. Nasrin, K. H. M. N. H. Nazir, M. T. Rahman" and M. M. Alam \\ Department of Microbiology and Hygiene, ${ }^{1}$ Department of Medicine, Faculty of Veterinary Science, Bangladesh \\ Agricultural University, Mymensingh-2202, Bangladesh \\ *Corresponding author's e-mail address: tanvirahman@gmail.com
}

\begin{abstract}
The study was carried out with 73 human originated samples viz. surgical wound swab, pus, burn ulcer exudates, aural swab and diabetic ulcer exudates collected over a period of 5 months starting from September 2006 to identify and characterize enterotoxins and toxic shock syndrome toxin-1 (TSST-1) producing coagulase-positive S. aureus (CPSA) by Reverse Latex agglutination test, in which $30(41.10 \%)$ were found as CPSA. Among the 30 CPSA isolates, $22(73.33 \%), 6(20 \%)$ and 2 $(6.67 \%)$ were golden-yellow, yellow and whitish pigment producers, respectively and $29(96.67 \%)$ isolates indicated $\beta$ hemolysis on blood agar speculating their ability to produce $\beta$-hemolysin. A total of 30 CPSA were checked for enterotoxin and TSST-1 production of which $5(16.67 \%)$ and $1(3.33 \%)$ isolates produced enterotoxin-A and TSST-1, respectively. Other produced multiple toxins in which $2(6.67 \%)$ produced both enterotoxin A and enterotoxin B, $2(6.67 \%)$ produced both enterotoxin $\mathrm{C}$ and enterotoxin D and $2(6.67 \%)$ produced both enterotoxin C and TSST-1. Antibiotic resistant pattern of the CPSA indicated that $83.33 \%$ isolates were resistant to penicillin-G and $70 \%$ to sulphamethoxazole. On the other hand, the results demonstrated that gentamicin, spiramicin, ciprofloxacin, oxacillin, oxytetracycline and streptomycin might be used for the treatment of $S$. aureus infection. Few multiple antibiotic resistant CPSA were also identified. The prevalence of methicillin resistance S. aureus (MRSA) was $23.33 \%$.
\end{abstract}

Key words: CPSA, reverse-latex-agglutination test, enterotoxins, TSST-1, MRSA

\section{INTRODUCTION}

Staphylococcus aureus is an opportunistic bacterial pathogen distributed widely in nature. Pathogenic $S$. aureus are typically coagulase positive. In human, they are generally recognized as commensals and the pathogenic S. aureus causes a variety of pyogenic infections such as food poisoning and toxic shock syndrome (Parker and Duerden, 1990). Pathogenic S. aureus produce potent toxins including heat stable six immunologic types of enterotoxins (types A-F), hemolysin, TSST-1, and exfoliation (Warren, 2005). Food poisoning caused by staphylococcal enterotoxins is characterized by prominent vomiting and watery non-bloody diarrhea. TSST-1 causes toxic shock, especially in tampon-using menstruating women or in individuals with wound infections. Emergences of multiple drug resistant $S$. aureus from human origin including MRSA are of great concern for human health due to difficulties in the selection of effective antibiotics to cure staphylococcal infection. Although S. aureus has been isolated in Bangladesh from different sources, however, there is lack of adequate information on their toxigenic nature. The purpose of this study was to detect and characterize enterotoxigenic and TSST-1 producing S. aureus from human origin.

\section{MATERIALS AND METHODS}

The study was conducted in the laboratory of the Department of Microbiology and Hygiene and in the laboratory of the Department of Medicine, Bangladesh Agricultural University (BAU), Mymensingh, during the period from September 2006 to April 2007. 


\section{Sources of samples}

A total of 73 samples such as wound swab, pus and exudates from diabetic burn ulcers and aural swab of patients were collected from Mymensingh Medical College (MMC) with proper aseptic precautions.

\section{Media used for culture}

Both commercially available and laboratory made media were used for the isolation, identification and characterization of $S$. aureus. The solid media used were blood agar (BA, HiMedia), nutrient agar (NA, HiMedia), mannitol salt agar (MSA, HiMedia) and Muller Hinton agar (MHA, Oxoid). The broths used were brain heart infusion broth (BHIB, HiMedia) and nutrient broth (NA, HiMedia). All the media were prepared according to the instructions of the manufacturer(s).

\section{Isolation of coagulase positive S. aureus}

S. aureus were isolated based on their morphological, staining and cultural characteristics following the procedures of Cheesbrough (1985). Coagulase test was performed using human plasma to detect the CPSA as described by Carter (1979).

\section{Test for pigment production and hemolytic activity}

Pigment production and hemolytic activity of S. aureus were observed on NA and BA media, respectively, according to the procedures of Chatterjee et al. (1990). $\beta$-hemolysis was indicated by the complete clear zones of hemolysis around the colony on BA.

\section{Reverse latex agglutination test procedure}

Reverse latex agglutination test was performed according to the method of Pinto et al. (2004). In brief, the single pure colony of CPSA isolate was inoculated into test tube containing $5 \mathrm{ml}$ BHIB and incubated aerobically at $37^{\circ} \mathrm{C}$ for $24 \mathrm{~h}$. After incubation, the broth culture was transferred into an eppendorf tube and centrifuged at 10,000 rpm for 5 minutes. The supernatant containing the toxins were collected. The test was done in V-shaped 96 well micro-plates. An amount of $25 \mu 1$ of PBS was poured in each well and $25 \mu 1$ of supernatant fluid was then added into each well of first row and subsequently a 2 fold dilution was made. Type specific pink colored antibody $(25 \mu 1)$ (Denka Seiken, Japan) was added to each well of particular column. The micro-plates were kept on an electric shaker for few seconds and kept at room temperature for overnight. Finally, agglutination reaction was observed. In positive cases, antigen-antibody bindings occurred and the pink color disappeared.

\section{Determination of antibiotic sensitivity pattern}

Antibiotic sensitivity test of the isolated CPSA was done by disc diffusion method using the Kirby-Bauser technique (Bauser et al., 1966) as per recommendation of National Committee for Clinical Laboratory Standards (NCCLS, 1997). The entire test was performed on MHA (pH 7.2-7.4). The name of antibiotics (manufactured by Oxoid Ltd. Basingstoke, Hampshire, England) and their concentrations were: penicillin-G (10 $\mu \mathrm{g} / \mathrm{disc})$, spiramycin $(100 \mu \mathrm{g} / \mathrm{disc})$, amoxycillin $(25 \mu \mathrm{g} / \mathrm{disc})$, oxytetracycline $(30 \mu \mathrm{g} / \mathrm{disc})$, oxacillin $(10 \mu \mathrm{g} / \mathrm{disc})$, gentamicin $(120 \mu \mathrm{g} / \mathrm{disc})$, ciprofloxacin $(5 \mu \mathrm{g} / \mathrm{disc})$, sulphamethoxazole $(25 \mu \mathrm{g} / \mathrm{disc})$ and streptomycin $(10$ $\mu \mathrm{g} / \mathrm{disc})$. The MRSA were detected by their ability of being resistant against oxacillin as described by Walther $e t$ al. (2006).

\section{RESULTS AND DISCUSSION}

\section{Prevalence of CPSA}

S. aureus is one of the important etiological agents responsible for pyogenic infection in man. Staphylococcal organisms are mainly associated with skin, gland and mucous membranes of man and animals. In the present study CPSA was isolated from pus, wound swab, aural swab, burn ulcers and diabetic burn ulcer exudates collected from human. Among the 73 samples, 30 (41.10\%) were positive for the presence of CPSA (Table 1). As the CPSA are usually pathogenic in nature hence, their presence indicates potential health risk for man. Aycicek et al. (2005) found 9.4\% prevalence of CPSA by testing a total of 512 samples originating from human hands; however, Fabiano et al. (2005) reported 36\% prevalence of CPSA in human skin samples. 
Enterotoxigenic Staphylococcus aureus

Table 1. Prevalence of CPSA in human sample

\begin{tabular}{|llll|}
\hline Sources of samples & No. of samples & CPSA positive & Prevalence (\%) \\
\hline Surgical wound swab & 34 & 13 & 38.24 \\
Pus & 14 & 9 & 64.29 \\
Burn ulcer exudates & 11 & 2 & 18.18 \\
Aural swab & 9 & 5 & 55.56 \\
Diabetic ulcer exudates & 5 & 1 & 20.00 \\
\hline Overall & 73 & 30 & 41.10 \\
\hline
\end{tabular}

\section{Pigment production and hemolytic activity}

Based on pigment production on nutrient agar it was observed that CPSA produced three distinct types of pigments. Among the 30 CPSA, 22 (73.33\%), 6 (20.00\%) and 2 (6.67\%) produced golden yellow, yellow and whitish pigmented colonies, respectivley (Table 2). Although variable production by CPSA isolated from bovine has been reported (Chatterjee et al., 1990), however, to our knowledge, there is no published information available on pigment production by human isolates. Therefore, the production of pigment alone cannot be regarded as a satisfactory criterion to indicate the coagulase status of CPSA.

Based on hemolytic activity on blood agar it was found that out of 30 CPSA, 29 (96.67\%) produced $\beta$ hemolysis (Table 2 ) indicating their ability to produce $\beta$-hemolysin toxin.

Table 2. Pigment production and hemolytic activity of CPSA

\begin{tabular}{|l|l|lll|l|}
\hline Sources of samples & No. of & \multicolumn{2}{|l|}{ Pigment production: $\mathrm{n}(\%)$} & \multirow{2}{*}{$\beta$-Hamolysis } \\
\cline { 3 - 5 } & CPSA & Golden yellow & Yellow & Whitish & \\
\hline Wound swab & 13 & 9 & 2 & 2 & 13 \\
Pus & 9 & 8 & 1 & 0 & 9 \\
Burn ulcer exudates & 2 & 1 & 1 & 0 & 2 \\
Aural swab & 5 & 3 & 2 & 0 & 4 \\
Diabetic ulcer exudates & 1 & 1 & 0 & 0 & 1 \\
\hline Overall & 30 & $22(73.33 \%)$ & $6(20.00 \%)$ & $2(6.67 \%)$ & $29(96.67 \%)$ \\
\hline
\end{tabular}

\section{Detection of enterotoxins and TSST-1 producing CPSA}

Enterotoxigenic and TSST-1 producing CPSA were isolated in the present study using reverse latex agglutination test (Table 3 and 4). Reverse latex agglutination test has been used earlier successfully to detect staphylococcal enterotoxins and TSST-1 (Takeuchi et al., 1998). Fueyo et al. (2005) isolated enterotoxins A, B, $\mathrm{C}$ and D, and TSST-1 producing S. aureus from human. Fotta et al. (2000) and Schmitz et al. (1997) isolated enterotoxins A, B, C and D, and TSST-1 producing S. aureus isolated from foods, equipment and personnel working in meat processing plant. Type $\mathrm{C}$ enterotoxin was the commonest while type $\mathrm{D}$ was the least common (Lim et al., 1982), however, in the present study, among the 30 CPSA isolated from human $5(16.67 \%)$ were positive for enterotoxin A and one (3.33\%) for TSST-1 (Table 3) when analyzed to detect isolates able to produce single toxin production.

Table 3. Prevalence of enterotoxin (A-D) and TSST-1 producing of human (single toxin production)

\begin{tabular}{|l|l|llll|l|}
\hline Sources of samples & \multirow{2}{*}{ No. of CPSA } & Enterotoxins & & & \multirow{2}{*}{ TSST-1 } \\
\cline { 3 - 6 } & & A & B & C & D & \\
\hline Surgical wound swab & 13 & 2 & 0 & 0 & 0 & 1 \\
Pus & 9 & 1 & 0 & 0 & 0 & 0 \\
Aural swab & 5 & 1 & 0 & 0 & 0 & 0 \\
Diabetic ulcer exudates & 1 & 0 & 0 & 0 & 0 & 0 \\
Burn ulcer exudates & 2 & 10 & 0 & 0 & 0 & 0 \\
\hline Overall & $\mathbf{3 0}$ & $\mathbf{5 ( 1 6 . 6 7 \% )}$ & $\mathbf{0}$ & $\mathbf{0}$ & $\mathbf{0}$ & $\mathbf{1 ( 3 . 3 3 \% )}$ \\
\hline
\end{tabular}


Table 4. Prevalence of enterotoxin (A-D) and TSST-1 producing CPSA in human (multiple toxins production)

\begin{tabular}{|l|l|l|l|l|l|l|l|}
\hline Sources of samples & \multirow{2}{*}{$\begin{array}{l}\text { No. of } \\
\text { CPSA }\end{array}$} & \multicolumn{2}{l}{ Enterotoxin (A+B) } & \multicolumn{2}{l|}{ Enterotoxin (C+D) } & \multicolumn{2}{l|}{ Enterotoxin (C+TSST-1) } \\
\cline { 3 - 9 } & No. & $\%$ & No. & $\%$ & No. & $\%$ \\
\hline Surgical Wound swab & 13 & 0 & & 0 & & 0 & \\
\hline Pus & 9 & 0 & 0.00 & 2 & 22.22 & 2 & 22.22 \\
\hline Aural swab & 5 & 1 & 20.00 & 0 & 0.00 & 0 & 0.00 \\
\hline Diabetic ulcer exudates & 1 & 0 & 0.00 & 0 & 0.00 & 0 & 0.00 \\
\hline Burn ulcer exudates & 2 & 1 & 50.00 & 0 & 0.00 & 0 & 0.00 \\
\hline Overall & 30 & 2 & 6.67 & 2 & 6.67 & 2 & 6.67 \\
\hline
\end{tabular}

None of the CPSA was positive for enterotoxins B, C and D. Few isolates of CPSA were found positive for production of more than one toxin (Table 4). Ability of $S$. aureus to produce more than one toxin has earlier been reported by Aliu and Bergdoll (1988). Thirty-five of the 50 S. aureus isolated by them from human produced either enterotoxin A or C or both in addition to TSST-1. Fotta et al. (2000) studied the enterotoxin producing capacity of $162 \mathrm{~S}$. aureus isolates from foods, equipment and workers from meat processing plants of which $75.2 \%$ isolates produced one type of enterotoxin and $24.8 \%$ produced two or more types of enterotoxins. Type $\mathrm{C}$ enterotoxin was the commonest (42.7\%) while type D was the least common (2.5\%). A total of $5.98 \%$ isolates produced more than three enterotoxins. Here, we demonstrated clearly the production of enterotoxins and TSST-1 by CPSA isolate from human origin. Present study provides a basis on the toxigenic nature of CPSA isolated from human origin. Although few isolates were found positive for enterotoxins and TSST-1, however, their specific role in disease processes in man could not be evaluated and need further investigation.

\section{Antibiotic resistance pattern of CPSA}

The resistant pattern of the isolated CPSA to antibiotic used here were variable. Highest resistant was observed against penicillin-G and sulphamethoxazole. A total of $83.33 \%$ human isolates were resistant to penicillin-G, whereas $70 \%$ to sulphamethoxazole (Table 5).

Table 5. Resistance pattern of CPSA isolates from human samples against various antibiotics

\begin{tabular}{|c|c|c|c|c|c|c|c|c|c|c|}
\hline \multirow[t]{2}{*}{ Source of CPSA } & \multirow{2}{*}{$\begin{array}{l}\text { No. of } \\
\text { CPSA }\end{array}$} & \multicolumn{9}{|c|}{ Organism(s) found resistant [Number (\%)] } \\
\hline & & $P$ & $\mathrm{CN}$ & AML & SP & CIP & $\mathrm{RL}$ & OX & OT & $\mathrm{S}$ \\
\hline Surgical wound swab & 13 & 11 & 3 & 4 & 1 & 2 & 9 & 4 & 1 & 2 \\
\hline Pus & 9 & 7 & 2 & 2 & 1 & 2 & 6 & 2 & 0 & 1 \\
\hline Burn ulcer exudate & 2 & 2 & 0 & 0 & 0 & 0 & 2 & 0 & 0 & 0 \\
\hline Aural swab & 5 & 4 & 1 & 1 & 0 & 0 & 3 & 1 & 0 & 0 \\
\hline Diabetic ulcer exudate & 1 & 1 & 0 & 0 & 0 & 0 & 1 & 0 & 0 & 0 \\
\hline Total & 30 & \begin{tabular}{l|}
25 \\
$(83.33)$ \\
\end{tabular} & $\begin{array}{l}6 \\
(20) \\
\end{array}$ & $\begin{array}{l}7 \\
(23.33) \\
\end{array}$ & $\begin{array}{l}2 \\
(6.67) \\
\end{array}$ & $\begin{array}{l}4 \\
(13.33) \\
\end{array}$ & $\begin{array}{l}21 \\
(70)\end{array}$ & $\begin{array}{l}7 \\
(23.33) \\
\end{array}$ & $\begin{array}{l}1 \\
(3.33)\end{array}$ & $\begin{array}{l}3 \\
(10)\end{array}$ \\
\hline
\end{tabular}

$\mathrm{P}=$ Penicillin-G, $\mathrm{SP}=$ Spiramicin, $\mathrm{OX}=$ Oxacillin, $\mathrm{CN}=$ Gentamicin, $\mathrm{CIP}=$ Ciprofloxacin, $\mathrm{OT}=$ Oxytetracycline, $\mathrm{AML}=$ Amoxycillin, $\mathrm{RL}=$ Sulphamethoxazole, $\mathrm{S}=$ Streptomycin. The isolates resistant against oxacillin were considered as MRSA as described by Walther et al. (2006).

The increased number of resistant CPSA to penicillin G and sulphamethoxazole might be linked to the long and extensive use of those antibiotics in human. On the other hand, spiramycin, oxytetracycline, streptomycin and ciprofloxacin could be used for the treatment of staphylococcal infection in human in Bangladesh. Kadlubowska et al. (2006) found CPSA as resistant against spiramycin and ciprofloxacin in Poland.

Several MRSA and multiple antibiotic resistant CPSA were identified in present study. The prevalence of MRSA was 23.33\% (Table 5), which was in support of Loeffler et al. (2005) and Kadlubowska et al. (2006) who found $17.9 \%$ and $70 \%$ MRSA positive cases of human origin, respectively. Manian (2003) reported MRSA from wound infection of human. The results indicated MRSA as common nosocomial pathogens of human. Cloning and sequencing of $m e c A$ gene responsible for methicillin resistance may be done from the MRSA isolated here to understand their molecular epidemiology. 


\section{ACKNOWLEDGEMENT}

The authors are very much thankful to Professor Dr. Nobumichi Kobayashi, Department of Hygiene, Sapporo Medical University, School of Medicine, Sapporo 060-8556, Japan for providing us the Reverse latex agglutination test kit as gift.

\section{REFERENCES}

1. Aliu B, and Bergdoll MS (1988). Characterization of staphylococci from patients with toxic shock syndrome. Journal of Clinical Microbiology 26 (11): 2427-2428.

2. Aycicek H, Cakiroglu S and Stevenson TH (2005). Incidence of Staphylococcus aureus in ready-to-eat meals from military cafeterias in Ankara, Turkey. Food Control 16 (6): 531-534.

3. Bauser AW, Kirby WMM, Sheris JC and Truck M (1966). Antibiotic susceptibility testing by a standardized single disk method. American Journal of Clinical Pathology 145: 225-230.

4. Carter GR (1979). Diagnostic Procedures in Veterinary Bacteriology and Mycology. $3^{\text {rd }}$ edn., Charles C. Thomas Publisher, USA. pp. 157-160, 410-411.

5. Chatterjee C, Nag NC and Roy JP (1990). Studies on coagulase status and biochemical characters of animal strains of staphylococci. Indian Journal of Animal Health 29 (2): 157-161.

6. Cheesbrough M (1985). Medical Laboratory Manual for Tropical Countries. Vol. II: Microbiology. pp. 400-480.

7. Fabiano TLT, Lemos MVF and Givisiez PEN (2005). Fluorescent amplified fragment length polymorphism genotyping of human and animal Staphylococcus aureus isolates from dairy farms with manual milking. Veterinary Microbiology 109 (1-2): 57-63.

8. Fotta M, Federicova J, Gondol J, Kalinacova V and Holeckova B (2000). Occurrence of enterotoxigenic Staphylococcus aureus strains. Slovensky Veterinarsky Casopis 25 (5): 291-293.

9. Fueyo JM, Mendoza MC and Martin MC (2005). Enterotoxins and toxic shock syndrome toxin in Staphylococcus aureus recovered from human nasal carriers and manually handled foods: epidemiological and genetic findings. Microbes and Infection 7 (2): 187-194

10. Kadlubowska AL, Russjan JK and Hryniewicz W (2006). Characteristics of Staphylococcus aureus strains isolated in Poland in 1996 to 2004 that were deficient in species-specific proteins. Journal of Clinical Microbiology 44 (11): 40184024.

11. Lim YS, Jegathesan M, and Koay AS (1982). Enterotoxin production by Staphylococcus aureus strains isolated from humans, foods and animals in Malaysia. Southeast Asian Journal of Tropical Medical Public Health 13 (1): 133-137.

12. Loeffler A, Boag, Sung J, Lindsay JA, Guardabassi L, Dalsgaard A, Smith H, Stevens KB and Lloyd DH (2005). Prevalence of methicillin-resistant Staphylococcus aureus among staff and pets in a small animal referral hospital in the UK. Journal of Antimicrobial Chemotherapy 56 (4): 692-697.

13. Manian FA (2003). Asymptomatic Nasal Carriage of Mupirocin-Resistant, Methicillin- Resistant Staphylococcus aureus (MRSA) in a Pet Dog Associated with MRSA Infection in Household Contacts. Clinical Infectious Diseases 36: 26-28.

14. NCCLS (1997). Performance standards for antimicrobial susceptibility testing supplement M100-S10., Wayne, Pa.

15. Parker MT and Duerden BI (1990). Tropley and Wilsons Principles of Bacteriology, Virology and Immunity. Vol. 2. $8^{\text {th }}$ edn., Butler and Tanner Ltd. Great Britain. pp. 161-186.

16. Pinto AD, Forte VT, Ciccarese G, Conversano MC and Tantillo GM (2004). Comparison of reverse passive latex agglutination test and immunoblotting for detection of staphylococcal enterotoxin a and b. Journal of Food Safety 24 (4): 231.

17. Schmitz FJ, MacKenzie CR, Geisel R, Wagner S, Idel H, Verhoef J, Hadding U and Heinz HP (1997). Enterotoxin and toxic shock syndrome toxin-1 production of methicillin resistant and methicillin sensitive Staphylococcus aureus strains. European Journal of Epidemiology 13 (6): 699-708.

18. Takeuchi S, Ishiguro K, Ikegami M, Kaidoh T, and Hayakawa Y (1998). Production of toxic shock syndrome toxin by Staphylococcus aureus isolated from mastitic cow's milk and farm bulk milk. Veterinary Microbiology 59 (4): 251-258.

19. Walther B, Friedrich AW, Brunnberg L, Wieler LH and Lubke-Becker A (2006). Methicillin-resistant Staphylococcus aureus (MRSA) in veterinary medicine: a New Emerging Pathogen. Berliner-und-Munchener-TierarztlicheWochenschrift 119 (5/6): 222-232.

20. Warren L (2005). Medical Microbiology and Immunology. $8^{\text {th }}$ edn., p: 105. 